\section{Endoscopic Management of Postpolypectomy Perforation}

Traditionally, open surgery was the treatment of choice for upper gastrointestinal tract perforation except in selected cases (1). We report a case of endoscopic management of perforation after a snare cautery removal of a fundal gastric polyp.

An 83-year-old woman was admitted to hospital due to passing tarry stool. Gastroscopy revealed a $1.5 \mathrm{~cm}$ antral ulcer and a $2 \mathrm{~cm}$ sessile polyp at the fundus. The base of the polyp was injected with epinephrine and polypectomy was accomplished with a snare cautery. A $5 \mathrm{~mm}$ perforation was noted at the end of procedure (Figure 1). In view of her poor surgical risk, four metallic clips (Olympus MD-850, Tokyo, Japan) were applied with a clip-fixing catheter (Olympus HX-6 UR-1, Tokyo, Japan) to close the perforation endoscopically. The clipped area was reinforced by spraying $5 \mathrm{ml}$ fibrin glue (Tisseel kit, Immuno AG, Vienna, Austria) (Figure 2). She was monitored in the surgical ward after the procedure and water-soluble contrast study 24 hours later showed no leakage. She made an uneventful recovery and pathology confirmed a completely excised leiomyoma.

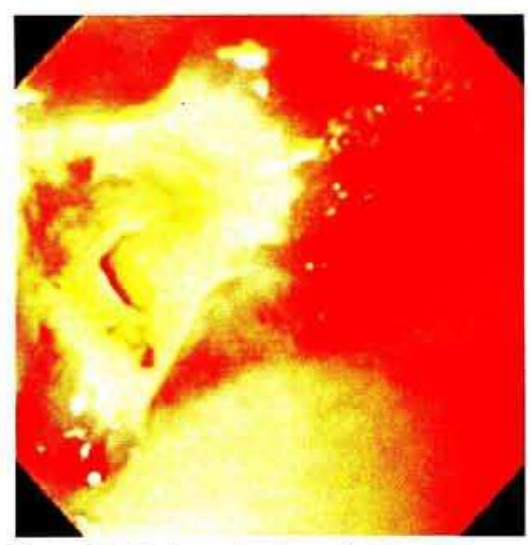

Figure 1: Endoscopic view showing the perforation after polypectomy.
Binmoeller et al. first used metallic clips to close gastric perforation in 1993 (2). We confirmed the technique is feasible and safe. Endoscopic management is particularly suitable for iatrogenic perforations because these perforations are usually small and peritoneal contamination is minimal due to early recognition. This minimally invasive technique can save poor surgical risk patients from a possibly hazardous laparotomy. Fibrin glue was demonstrated as effective as suture repair in perforated duodenal ulcer (3). The additional usage of fibrin glue in this case further secures the repair. Although endoscopic management is feasible, the early involvement of experienced surgeons is necessary in patients with iatrogenic perforations.

D. W. H. Lee', A. C. W. Chan', C. W. Lai ${ }^{2}$, Y. H. Lam', S. C. S. Chung'

'Dept. of Surgery

${ }^{2}$ Dept. of Medicine

The Chinese University of Hong Kong, Prince of Wales Hospital, Hong Kong

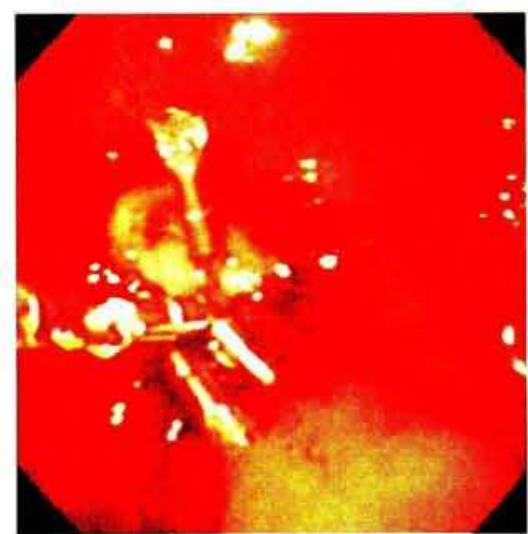

Figure 2: Endoscopic view after clip application.

\section{References}

1. Crofts TJ, Park KG, Steele RJ, et al. A randomized trial of nonoperative treatment for perforated peptic ulcer. $\mathrm{N}$ Engl J Med 1989; 320: 970 - 3 .

2. Binmoeller KF, Grimm H, Soehendra N. Endoscopic closure of a perforation using metallic clips after snare excision of a gastric leiomyoma. Gastrointest Endosc 1993; 39: 172-4.

3. Lau WY, Leung, KL, Kwong KH, et al. A randomized study comparing laparoscopic versus open repair of perforated peptic ulcer using suture or sutureless technique. Ann Surg 1996; 224: 131-8.

Corresponding Author

S. C. S. Chung, M.D.

Dept. of Surgery

The Chinese University of Hong Kong Prince of Wales Hospital

Shatin

Hong Kong

Fax: + 852-26-350075 